\title{
Diarrea Aguda por Rotavirus: Algunos aspectos clínicos
}

\author{
Drs. Aquiles Calderón. * Juan Macaya,* Luis Fidel Avendaño. ** Ingebor Prenzel.* \\ Josế Manuel Ojeda** y T.M. Eliana Duarte."
}

\begin{abstract}
ABSTR ACT
The use of viral nucleic acid elec'truphoresis lechnjuge has lead the authors to detect rotalirus in twenty unt of fifty

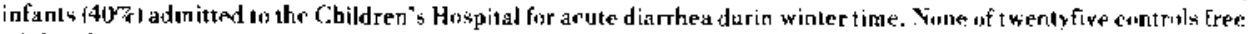
of diarchea was positive for rotacirus. Enterupathugenje bacteria were isulated with the sume frecupuency in both. diurrhes and control groups.

The thatin rliniral features of these i wenty patients. with acute diurrhea. rotavirus posilive simols. Hre as follows: age

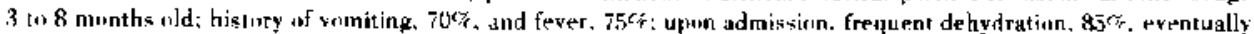

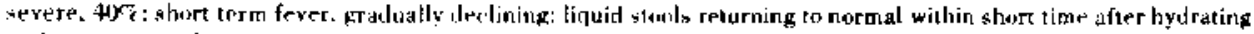
and progkresive feeding therajy.
\end{abstract}

El desarrollo de nuevas técnicas para detección de Rotavirus está permitiendo reducir el alto porcentaje de diarreas agudas infecciosas de causa desconocida. En efecto, numerosas publicaciones extranjeras muestran aislamiento de Rotavirus en $31 \%$ a $89 \%$ de los casos de diarreas infantiles, ${ }^{1}$ constituyendo este grupo de virus el agente único más frecuentemente relacionado con esta patología. ${ }^{2}$

La aplicactón de la técnica de electroforesis del ácido nucleico viral descrita por Espejo y Cols ${ }^{3}$ nos permitió detectar la presencia de Rotavirus en el $40 \%$ de los lactantes hospitalizados por diarrea aguda en el hospital Roberto del Río, en el invierno de 1979.4

Sólo en muy contadas ocasiones puede presumirse la etiología de la diarrea aguda basándose en la

*Departamento de Pedistría. Hogpilal Roberı del Río.

**Departamento Micrabiología y Parasilologia, Sección Vírologia.

Facultad de Medicina Norte. Universidad de Chile.

Trabajo financiado con el Propecto M 467-79l del Servicio de

Desarrollo Cientificu. Artistico y de Cooperación Internacional. signosintomatologia presente. Sin embargo, nos pareció importante tratar de establecer una forma clinica de presentación de la diarrea aguda que pudjera relacionarse con una etiologia específica, por las inherentes implicancias pronósticas y terapéutícas. En este sentido se analizaron los aspectos clínicos más destacados de los lactantes con diarrea en los que se ha detectado Rotavirus.

\section{MATERIAL Y METODO}

Se analizan 50 nin̄os ingresados a la Unidad de Lactantes del Hospital Roberto del Río, entre el 19 de Junio y el 19 de septiembre de 1979, con diagnóstico de diarrea aguda. Se registraron los datos clínicos de nuestro interés (identificación, edad, sexo, estado nutritivo, antecedentes de vómitos y fiebre, características de las deposiciones y de la fiebre, evolución y otros) y se recolectaron dos muestras de deposiciones en los primeros dias de ingreso para estudio microbiológico. Se constituyó un grupo control, con 25 
Jactantes hospitalizados por patologia no digestiva. que se sometió a igual metódica para búsqueda de agentes patógenos en deposiciones.

El estudio virológico se limitó a la detección de Rotavirus mediante la técnica de electroforesis del ácido nucleico viral descrita anteriormente. ${ }^{3.4} \mathrm{La}$ búsqueda de bacterias enteropatógenas se realizó tomando las muestras en medio de transporte Cary Blair y sembrado en placa en medio MacConkey y SS; la identificación se hizo por las propiedades bioquímicas en forma habitual; se repicaron 5 colonias Lactosa + confirmando E coli por características bioquímicas, $y$ se tipificaron con mezclas de antisueros preparados por el Instituto Bacteriológico de Chile. Las cepas de Salmonella y Shigella se confirmaron en el Centro de Referencia, en el Instituto Bacteriológico. La tabulación de los hechos clínicos la efectuó uno de los investigadores sin conocimiento de los resultados de bacteriología o virología. Los exámenes microbiológicos se hicieron igualmente en forma independiente por los distintos autores.

El material en estudio quedó constituido por 50 lactantes con diarrea, en 20 de los cuales se detectó Rotavirus (40\%). Se analiza fundamentalmente el grupo "con aislamiento" de Rotavirus. La edad varió entre 0 y 23 meses, con tendencia a concentrarse entre 3 y 8 meses (Tabla $\mathrm{N} .{ }^{0} 1$ ). La distribución por sexo fue homogénea y no hubo diferencias en el estado nutritivo (Tabla N. ${ }^{\circ}$ ).

\section{RESULTADOS}

El antecedente anamnéstico de fiebre y vómitos se

\section{Tabla N. ${ }^{0} 1$}

Detección de rotavirus en $\mathbf{5 0}$ lactantes hospitalizados por diarrea aguda. Santiago, invierno de 1979.

Distribución por edad

\begin{tabular}{lrrr}
\hline & & \multicolumn{3}{c}{ Rotavirus } \\
Edad & Casos & Positivo & Negativo \\
& & & 12 \\
$0-2 \mathrm{~m}$. & 15 & 3 & 6 \\
$3-5 \mathrm{~m}$. & 17 & 11 & 4 \\
$6-8 \mathrm{~m}$. & 7 & 3 & 4 \\
$9-11 \mathrm{~m}$. & 5 & 1 & 4 \\
$12 \mathrm{~m}$. y más & 6 & 2 & $30460 \%$ \\
\hline Total & 50 & 20 (40)
\end{tabular}

Tabla N. ${ }^{\circ} 2$

Detección de Rotavins en 50 lactantes hospitalizados por diarrea aguda. Santiago, invierno de 1979 Distribución por estado nutritivo

\begin{tabular}{lrrc}
\hline & Casos & \multicolumn{2}{c}{ Rotavirus } \\
& & Positivo & Negativo \\
\hline Eutrofia & 25 & 12 & 13 \\
Desnutrición I & 20 & 7 & 13 \\
Desnutrición II & 5 & 1 & 4 \\
\hline Total & 50 & 20 & 30 \\
\hline
\end{tabular}

observó en una alta proporción de los lactantes con aislamiento de Rotavirus; asimismo, este grupo mostró presencia de deshidratación en el $85 \%$ de los casos (Tabla N. ${ }^{\circ}$ ). Los signos de actividad diarreica -meteorismo, ruidos hidroséreos, borborigmo y bazuqueo- estuvieron presentes en todos los casos, catalogándose su intensidad entre leve y moderada. La duración intrahospitalaria de la diarrea se encuadró entre los márgenes de 1 a 8 dís, salvo un caso cuya duración fue 9 días en el grupo Rotavirus y seis enfermos en el grupo sin aislamiento del virus. Asi, de acuerdo al criterio de la Unidad de Lactantes, 5.6 se planteó el diagnóstico de diarrea de evolución tórpida o prolongada sólo en $5 / 30$ casos en el grupo sin Rotavirus. El síndrome disentérico se observó en $1 / 20$ casos con aislamiento exclusivo de Rotavinus y en $3 / 30$ lactantes $\sin$ Rotavirus, en los que tampoco

Tabla N. ${ }^{\circ} 3$

Signos y síntomas de ingreso en 50 lactantes hospitalizados por diarrea aguda. Santiago, inviemo de 1979. Distribución según detección de Rutavirus

\begin{tabular}{lcc}
\hline Signos y Síntomas & $\begin{array}{c}\text { Rotavirus } \\
\text { Positivo } \\
(20 \text { casos })\end{array}$ & $\begin{array}{c}\text { Rotavirus } \\
\text { Negativo } \\
(30 \text { casos) }\end{array}$ \\
\hline $\begin{array}{l}\text { ntecedentes de fiebre } \\
\begin{array}{l}\text { Antecedentes de vómitos } \\
\text { ravedad mediana o in- }\end{array}\end{array}$ & $14(70 \%)$ & $14(46.6 \%)$ \\
$\begin{array}{l}\text { Deshidratación } \\
\text { eshidratación mediana } \\
\text { intensa }\end{array}$ & $15(75 \%)$ & $18(46.6 \%)$ \\
\hline
\end{tabular}


se aisló bacteria enteropatógena. Durante la hospitalización no se observí fiebre o ésta fue de baja magnitud en forma similar en el grupo con aislamiento de Rotavirus $(9 / 20)$ y sin detección de virus $(18 / 30)$; cuando hubo tiebre evidente. generalmente cayó en lisis dentro de los primeros días $(8 / 20 \mathrm{Y} 9 / 30$ ). respectivamente.

Se aislaron bacterias enteropatógenas en $52 \%$ de los casos, tanto en el grupo con diarrea (26/50) corno en el grupo control (13/25). En el grupo con diarrea se comprobó $E$. coli enteropatógena en $11 / 20$ casos Rotavirus positivo ( $55 \%$ ) y en 13/30 lactantes Rotavinus negativos; debe agregarse a este último grupo un paciente con Shigella y otro con Salmonella typhymirium (total 15/30: 50\%). No se observó un serotipo predominante entre las $\mathbf{E}$. coli, encontrándose una amplia gama de ellos: 026, 044, 086, 0111, $0124,0125,0126,0127,0128$. Tampoco hubo diferencias en los serotipos en relación a la detección o no de Rotavirus. En el grupo "control sin diarrea" hubo $0 / 25$ aislamiento de Rotavirus.

\section{DISCUSION}

Nuestro material representa un grupo seleccionado de las diarreas agudas, pues el hecho de estar formado por lactantes hospitalizados implica una mayor severidad del cuadro clínico, en la que muchos factores como edad, estado nutritivo, condición socioeconómica, etc. pueden influir en las características del cuadro, tal yez más que el agente etiológico mismo.

Para el análisis hemos separado los pacientes en dos grupos, según eJ aislamiento de Rotavirus, puesto que la influencia de bacterias enteropatógenas parece muy pequeña, a juzgar por la semejanza de aislamiento en lactantes con diarrea y controles sin diarrea, o en diarreas con o sin detección de Rotavirus. Por otra parte, la técnica de electroforesis del ácido nucleico para diagnosticar Rotavirus requiere de la presencia del virus en altas concentraciones en las desposiciones, hecho que permite suponer la existencia de falsos negativos en el grupo "Rotavirus negativo". ${ }^{3}$ Por este motivo, nos parece más adecuado hacer un análisis detenido de los resultados en el grupo en el cual se detectó Rotavirus, y considerar al otro grupo sólo como un punto de referencia o comparación.

En el grupo con aislamiento de Rotavirus se observa una tendencia de los casos a concentrarse entre 3 y 8 meses de edad, especialmente entre 3 y 5 meses, hecho concordante con lo encontrado en otros países, ${ }^{7,8}$ y atribuida a una infección temprana del hombre con este virus. No se observaron diferencias significativas en cuanto a estado nutritivo y sexo. La mayor proporción de eutróficos en esta casuística parece deberse a las características de los pacientes que actualmente ingresan a la Unidad de Lactantes, en los cuales se ha notado una importante reducción de los desnutridos en la última década.

En esta experiencia no se pudo definir un cuadro clínico característico o modalidad distinta de la habitual en el sindrome diarreico aqudo. Sin embargo, a mendo de ensayo y de acuerdo a los datos tabulados, se pueden destacar algunos hechos interesantes, que una futura mayor casuística pudiera o no ratificar.

Existe el antecedente de un estado febril previo al ingreso al hospital en el $75 \%$ de los casos, aunque no se observa posteriormente en la hospitalización una curva febril característica; cuando esta fiebre reviste importancia, generalmente cae en lisis en el curso de los primeros días. El compromiso del estado general al ingreso se catalogó de intensidad mediana a grave en el $75 \%$ de los casos, aunque la evolución intrahospitalaria fue satisfactoria con el tratamiento hidratante y de realimentación progresiva de acuerdo a normas de la Unidad. La mejoría transcurrió en los plazos habituales y no hubo pacientes con evolución tórpida o prolongada. El compromiso del estado general al ingreso pudo estar relacionado con la alta frecuencia de fiebre y vómitos al comienzo de la enfermedad, lo que se reflejó en deshidratación en el $85 \%$ de los ingresos, la que revistió intensidad moderada o severa en $40 \%$. La característica predominante de las deposiciones fue la consistencia líquida con o sin mucosidades, que răpidamente evolucionaron a disgregadas; sólo en un caso se describió presencia de pus y sangre.

En cuanto a log agentes etiológicos del síndrome diarreico agudo encontrados en el presente trabajo debemos destacar que hubo aislamiento similar de bacterias enteropatógenas en los grupos con y $\sin$ diarrea, e incluso dentro del grupo con diarreas su distribución fue de $50 \%$ y $55 \%$ en los grupos Rotavinus negativo y positivo respectivamente. La E. coli serotipo clásico fue el agente aislado con mayor frecuencia en todos los grupos, por lo que se establece la necesidad de reevaluar el verdadero rol etiológico que este germen juega en la producción de la diarrea del lactante.

Finalmente destacamos el alto porcentaje de aislamiento del Rotavirus, lo que da a este agente una importancia que no se habia demostrado en nuestro medio. En un trabajo nacional recientemen- 
te publicado, ${ }^{7}$ empleando otra técnica, sólo se detectó Rotavirus en 2\%. Por otro lado estos resultados concuerdan con los publicados por numerosos autores extranjeros, ${ }^{1,2,7,8}$ aunque se hace necesari acumular una mayor experiencia para definir mejor los aspectos clínicos y epidemiológicos de la infección por Rotavirus en el país.

Sobre la base de esta experiencia de 50 casos, y teniendo presentes el reducido número de casos y la subjetividad de las observaciones clínicas que no permiten un riguroso análisis estadistico, nos atrevemos a describir sumariamente la "diarrea asnciada a Rotavirus" como una entidad clinica que se observa preferentemente en lactantes menores, sin relación a sexo o estado nutritivo, que comienza comúnmente con fiebre y vómitos, puede provocar algún gradode deshidratación, con deposiciones líquidas con o sin mucosidades, que evoluciona en plazos habituales con tratamiento de hidratación y realimentación progresiva.

\section{RESUMEN}

La aplicación de la técnica de electroforesis del ácido nucleico viral nos permitió detectar Rotavirus en $20(40 \%)$ de 50 lactantes hospitalizados en invierno por diarrea aguda. No se aisló Rotavirus en grupo control sin diarrea de 25 lactantes. El estudio de bacterias enteropatógenas mostró cifras semejantes en grupos con y sin diarrea.

Se destacan los aspectos clínicos más impor- tantes de estos 20 lactantes con diarrea con detección de Rotavirus en deposiciones: edades predominantes entre 3 y 8 meses; antecedentes anamnésticos de vómitos ( $75 \%$ ) y fiebre $(70 \%$ ): frecuente deshidratación $(85 \%)$ al ingreso, que puede revestir carácter severa ( $40 \%$ ); fiebre de corta duración que tiende a caer en lisis: deposiciones líquidas que evolucionan en plazos normales con tratamiento de hidratación y realimentación progresiva.

\section{REFEREVICIAS}

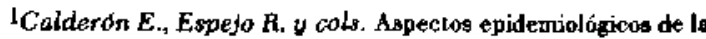
Gastroenteritis producida por Rotavirus. Bol. Méd. Hosp. Intant. (Méx.) 35: 45, 1978.

${ }^{2}$ Middileton P. Rotavirus: Clinicgl Observations and Díżosis of Gastroenteritis. En Kurstak $E$ and Kurstak C. Comparative Diagnosis of Viral Diseases, Chapter 11. New York, Acedemic Press 1977.

3Espejo R., Romero P., Calderón E. u Gonzalez N. Diagnóstico de rotovirus por electroforesis del RNA viral. Bol. Méd. Hosp. Infant (Méx.) 35: 323, 1978.

${ }^{4}$ Avendaño LF, Ojeda JM, Calderón A., Macaya J., Prenzel I V Duarte E. Detección de Ratavirus en lactantes hospitalizados por diarrea. Rev. Méd. Chile (En prensaj.

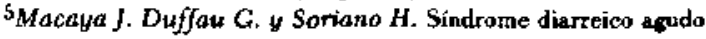
con deshidratación del lactanie. Evolución torpida. Metódica de estudio. Pediatría 15: 4B8, 1972.

${ }^{6}$ Calderón A., Goldenberg E. y col. Síndrome Diarreico Agudo de evolución lórpida. Análisis clínico de 100 pacientes. Pediatría 17: 95.1974.

${ }^{7}$ Davidson CP, Bishop RF et al. Importance of a new virul in acule sporadic enteritis in children. Lancet 1: 242, 1975.

${ }^{8}$ Muchintk G. y Grinstein S. Rotavinus en Buenos Aires. República Argenting. Comunicación en $84^{\circ}$ Congreso Latinoamericano Microbiología. Viña del Mar, Chile, Oct. 1979.

9 Aránguiz P., Duffau G., Curotta D. y Vergara MI. Síndrome diarreico agudo del laciante por Rotavirus. Pediatria 22: 27. 1979. 